\title{
Activity Based Trip Generation Forecasting for a Suburban Area
}

\author{
Tissa U. Liyanage and Amal S. Kumarage
}

\begin{abstract}
Travel patterns in suburban areas are different from those of other areas as the characteristics of activities are specific to a particular area. The distribution of such activities in an area may be found in terms of the economic activities of the households and their social attributes such as age, sex, educational level etc, denoting the intensity of engagement in these activities. On the other hand the level of activity in an area is also determined by the supply of facilities for such activities, such as availability of transport, employment opportunities, commercial and service facilities and recreational facilities, found in the given area, It has been observed that most of these supply functions do not vary significantly in the short term, a concept which has been used since the very early stages of travel forecast modelling. Therefore it has been found, that travel behaviour in a given area can be forecasted using primarily, the activity characteristics, of its population, as the demand variable.
\end{abstract}

This research paper is an attempt to forecast the travel behaviour of a suburban community, based on their social and economic activity status. It is based on an empirical analysis of travel demand data and the corresponding socio-economic activity profile of 30 Gramaseva Niladhari Divisions (GNDs) in a suburban area of Colombo. The results based on a category analysis between these variables, indicate the possibility of estimating the aggregate trip rates of a GND, based on its population classified by groups engaged in different socio-economic activities. The paper concludes by determining trip generation rates for different socio-economic households, based on their aggregate activity profile. Furthermore, that this method could be used for estimating trip generation in any suburban area wherein such data are available. .

Keywords: Category Analysis, Urban Travel Demand Forecasting, Suburban Area

\section{Introduction}

The socio-economic activities of an area are different from that of other areas in a country due to the variation of the socio economic characteristics. These activities also indicate the economic characteristics of an area. The population of an area can be disaggregated by employment, education and economically inactive occupations [2]. These different categories have a different level of potential to make day to day trips. In other words trip rates by such categories depend on their respective economic activities. Also they become decisive factors for mode selection for such trips. All these indicate the possibility of explaining the trip generation behaviour of an area based on the economic activities of its population.

The different areas in a state or a province can be categorised as urban, suburban, and exurbs [1]. These can be categorised mainly, based on the population densities of such areas and generally, the socio economic distribution. It has been observed by early research that similar levels of urban population densities are also likely to have similar socio economic characteristics among them. The similarity of the above factors among different areas is related to the concept called "spatial homogeneity" of urban activities [7]. The assumption of spatial homogeneity of urban areas helps to reduce the need to collect large numbers of data requirement for making traffic forecasting [5]. Hence this paper attempts to establish a simpler method of calibration for developing the relationship to explain trip generation behaviour by using socio economic attributes in identifying when spatially homogenous zones may be formulated.

The socio economic data in suburban areas in Sri Lanka are available with the Department of Census and Statistics. These data are collected

\footnotetext{
Eng. Tissa U. Liyanage, C. Eng., MIE (SLj, B.Sc. Eng. (Hons) (Moratuwa), M.Eng. (Moratuwa), Research Assistant, Department of Civil Engineering, University of Moratuwa, Sri Lanka,

Eng. (Prof) Amal S. Kumarage, FCILT, B.Sc. Eng. (Hons) (Moratuwa), MIE (SL), PhD (Calgary), Professor of Civil Engineering, Department of Transport \& Logistics Management, University of Moratuwa, Sri Lanka.
} 
every 5 years Island wide and have also been used to make forecasts for future years. The basic assumption in this trip generation forecasting method is that the spatial homogeneity of activities in suburban areas is assumed to be the same for all suburban areas concerned. Then the prediction models of traffic forecasting based on socioeconomic attributes can be applied in any other suburban areas other than the study area.

The category analysis method for calibration of trip generation rates by individuals on an activity basis pursued in this research is applied in this method of trip generation forecasting. The smallest traffic analysis zone (TAZs) is taken as Gramaseva Niladhari Divisions (GND) as it is the smallest disaggregate unit for socioeconomic data [2].

\section{The Objectives}

The following are the objectives of this research paper.

- To introduce an activity based trip forecasting method using economic engagement of the population in a suburban area.

- To develop a simple model with available socio-economic data as a cost effective traffic forecasting method.

- To compare and evaluate the trip behaviour between different activity groups in suburban areas.

\section{Review of Activity Based Trip Generation Analysis}

There have been many researches carried out in the past for category analysis, based on household size and car ownership [11]. Also the relationship between trip generation and income of household/population has been modelled for many urban areas in developed countries in the past. The accuracy of the traffic forecasting based on category analysis has been lested in comparison with regression analysis in leoul metropolitan area [6] where car ownership has been analysed against household tize to forecast work trip rate per household in both the City of Seoul and the Kyonggi Frovince. Also these rates have been compared with a foreign case. The above research has revealed the importance of category analysis for an area with different activity behaviour from another for higher accuracy of the trip forecast model development. The number of workers and the number of persons in the household has been cross classified for trip rates by the Puget Regional Council recently [11]. The internal volume forecasting model (IVF) developed by Kristy and Rahi, has used employees and job positions per zone as the basis for trip generation [8]. Employment, income, education level and household size were among the variables that were generated in the micro simulation of urban travel demand forecasting by Goulias and Kitamura [4]. Population and employment estimates from state income tax roles, census data, electricity utility records and privately developed databases were geo-coded to TAZs for traffic forecasting in urban areas using GIS by Muglar and Quinn [10]. A Recent study of suburban travel forecasting based on a hybrid process of category analysis and regression modelling, has been carried out by Liyanage and Kumarage [9]. The variables used here are the household type and domestic electricity consumption, as a surrogate variable, for the combined income of households in a suburban community. The urban density characteristics such as employment, household, retail business etc are thought of as a surrogate variable for accessibility in metropolitan travel model systems [3]. All the above literature and much more has shown the importance of having activity based category analysis, for accurate travel forecasting, in urban areas.

\section{Methodology}

This analysis is based on empirical data collected from a household survey in the Maharagama suburban area. The trip rate of residents and their trip purpose was surveyed and recorded with the economic activity (employment type, unemployment, housework etc.,) involvements of individuals. Each trip was recorded with the mode of travel used for such trips. Therefore the trip rates for different categories of economic engagements could be analysed for each passenger vehicle type. The trip rates between one activity and another were analysed and found to be significantly different in most cases. Also the selection of mode for such trips was found to be significantly different for different categories of activity groups. The 
categories of activities are as defined in the publications of the Department of Census and Statistics (DCS), Sri Lanka [2].

Basically the three major categories of activity involvement defined in this study are, employment, educational and economically non active group. The different employment types are further categorised into three groups based on the income and the social status of (a) Professionals and Senior Managers, (b) Associate Professionals and (c) Clerks and Supporting Staff. The category analysis applied in this instance considers the average trips in each category on a daily basis. Finally, these trip rates by activity types are cross classified by vehicle types, so that the output of the analysis can be given as mode based trip rates per person per day.

\section{Data Collection}

The suburban area of Maharagama includes a wide range of socio economic activities ranging from agriculture to commercial land use. Also, the reason to select this as the study area is its geographical location in terms of proximity to Colombo and it being considered as an important suburb. The Maharagama Divisional Secretariat (DS) area has 41 Gramaseva Niladari Divisions (GNDs) and a land area of 37.35 square kilometres. The population in the study area is 175,428 . There are 78,106 economically active inhabitants and 81,061 economically inactive inhabitants in the study area. Of these, there are 73,131 employed persons and 4,975 unemployed persons. There are 26,262 students, 35,976 houseworkers, 6,140 retired persons, 4,514 persons unable to work, 8,169 persons defined as others and a further 2,135 persons whose activity status is not stated [2].

The primary data for the analysis was collected from a randomly selected sample of 2,210 households (7.2 per cent of total) in 30 Gramaseva Niladari (GN) divisions. Details of a total of 6,642 daily trips made by 9,304 occupants were recorded. The questionnaire included socio economic data such as employment, type of population, age, sex, and travel information of the occupants such as trips per day, mode of travel, travel destination and purpose.
The relationship developed between travel behaviour and socio-economic data could be used to forecast traffic volumes using data bases available in DCS [2]. In the future, the traffic forecasting is possible with projected data with population growth rates.

Table 1: Classification of activity involvement by type of economic engagement

\begin{tabular}{|c|l|l|}
\hline No & Activity Group & \multicolumn{1}{|c|}{ Activity Category } \\
\hline 1 & Employment & $\begin{array}{l}\text { Professionals and senior } \\
\text { managers }\end{array}$ \\
\cline { 3 - 3 } & & $\begin{array}{l}\text { Associate professionals } \\
\text { and clerks }\end{array}$ \\
\cline { 3 - 3 } & & Supporting staff \\
\cline { 3 - 3 } & & Own business \\
\hline 3 & \multirow{2}{*}{ Educational } & Pre-school \\
& & School \\
\cline { 3 - 3 } & \multirow{2}{*}{$\begin{array}{l}\text { Economically } \\
\text { Inactive }\end{array}$} & University and others \\
& & Housework \\
\cline { 3 - 3 } & & Retired \\
\cline { 3 - 3 } & & Unemployed \\
\cline { 3 - 3 } & & Non active \\
\hline
\end{tabular}

\section{Analysis}

The method of category analysis has been used to derive the trip rates of individuals, in the study area by the different activities they are engaged in. Thereafter these rates are cross classified with the mode of travel they use. Trip rates by the different activity groups by the different modes are shown graphically.

\subsection{Behaviour of Travel Pattern by Employment Group}

\subsubsection{Professionals and Senior Managers (Type 1)}

The results of the category analysis between the activity group and their mode selection are shown in Table 2 . The population category of professionals and senior managers (Type 1) indicate different mode selection behaviour in comparison with other employment categories (Figure 1).

This category has a high rate of trips by private transport modes as indicated in Figure 1. The $74 \%$ of trips made by private transport in this category includes $55 \%$ of car trips; which is the highest rate for car trips by any kind of activity category. The observed demand for public transport from Type 1 population is $25 \%$. There are no non motorised trips by this category. 


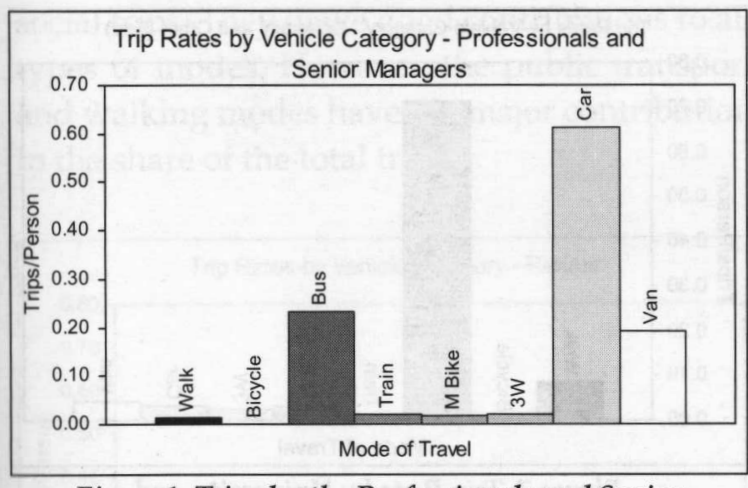

Figure 1: Trips by the Professionals and Senior Managers category

\subsubsection{Associate Professionals and Clerks (Type 2)}

This group of employment has the highest potential for using different modes for their day to day travel. A major percentage $(64 \%)$ of this category uses public transport (Figure 2). It has a highest rate of motor bike users (12\%) than any other category showing its middle income characteristics. The total share of private motorised transport trips is $29 \%$ with less than $10 \%$ making car trips. This indicates a lower affordability of four wheel vehicles by this group.

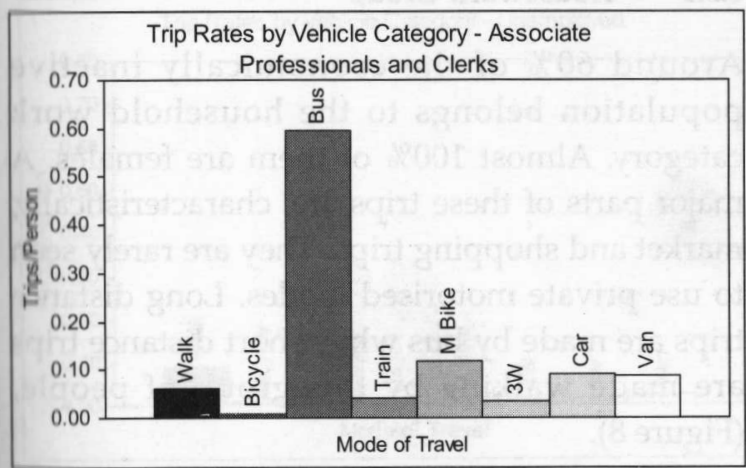

Figure 2: Trips by Associate Professionals and Clerks category

\subsubsection{Supporting Staff (Type 3)}

Almost $90 \%$ of persons in this category use public transport and non motorized transport. $17 \%$ of them walk. Four wheel owner users are not significant. However this category has a lower trip rate for buses than Type 2 employment. Also three wheelers have a significant share of the usage by people in this category. This category of employment has the lowest overall trip rate.

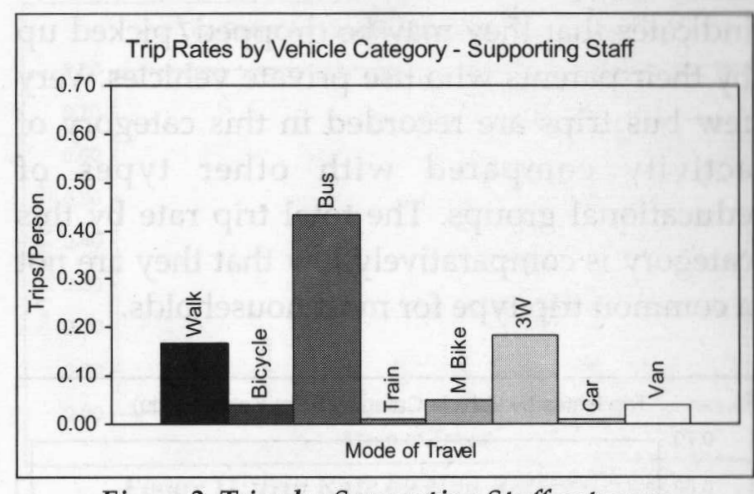

Figure 3: Trips by Supporting Staff category

\subsubsection{Business Employment (Type 4)}

Persons engaged in business employment have a well distributed mode selection as shown in Figure 4. All motorized private modes have almost equal shares. There are however no trips by trains. The trip length of this category is generally short as their business places are usually close to their place of residence. They use private motorised modes more than Type 2 category. Significant use of cars and vans are found which is second only to the Type 1 category of employment.

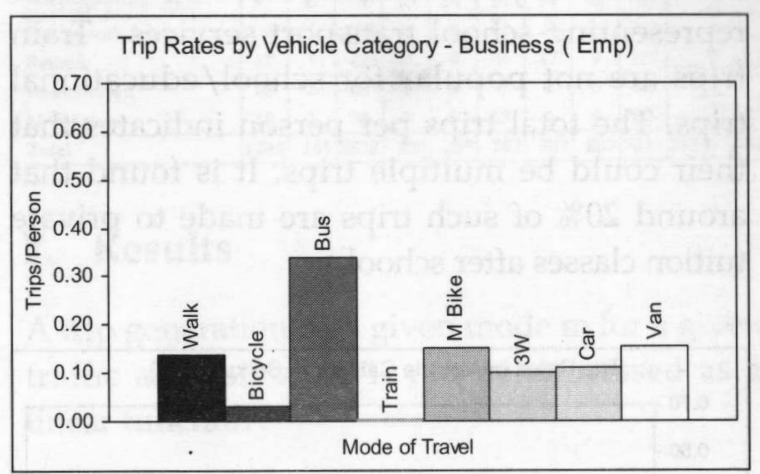

Figure 4: Trips by Business Employment category

\subsection{Behaviour of Travel Pattern by Educational Group}

Trip generation behaviour from those in educational activities is also very different from other activities with changes in terms of age of population also being observable.

\subsubsection{Pre-School Education Group}

Persons in the pre-school category have a very high trip rate for walking. This result indicates that they are attending schools close to their home when at an early age. However it is observed that even then, $35 \%$ of such trips are made by motorised private transport. This 
indicates that they may be dropped/picked up by their parents who use private vehicles. Very few bus trips are recorded in this category of activity compared with other types of educational groups. The total trip rate by this category is comparatively low that they are not a common trip type for most households.

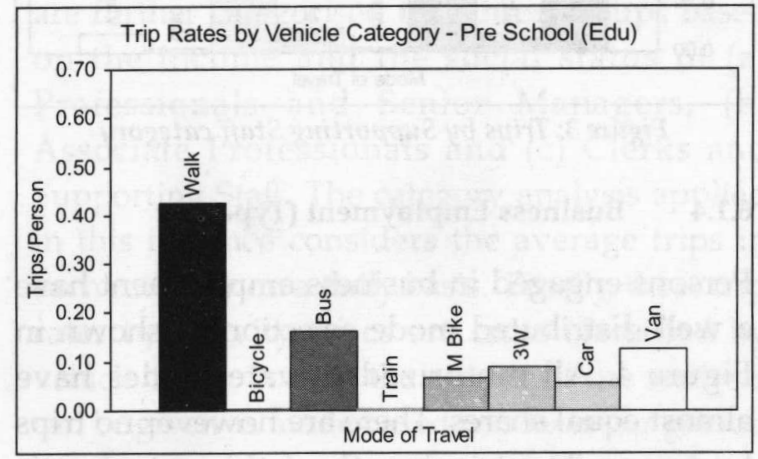

Figure 5: Trip Rate by Pre-School Education Group

\subsubsection{School Education Group}

As shown in Figure 6, public transport seems to play a major role in school educational trips as shown. Contributions from private motorised modes are very few. Van trips shown are those representing school transport services. Train trips are not popular for school/educational trips. The total trips per person indicates that their could be multiple trips. It is found that around $20 \%$ of such trips are made to private tuition classes after school.

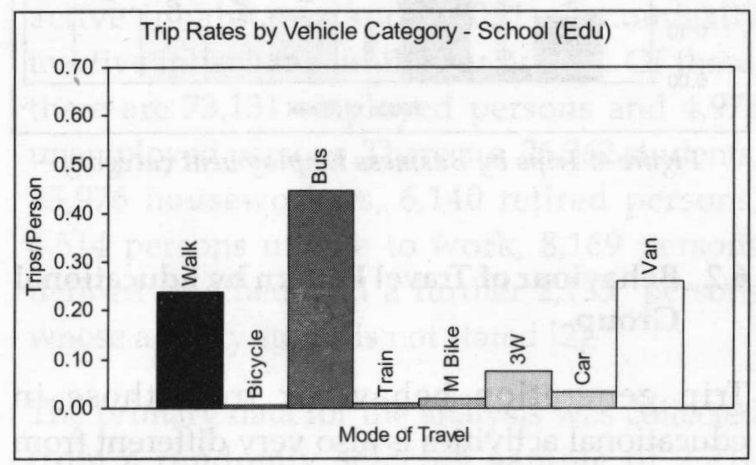

Figure 6: Trip Rate by School Education Group

\subsubsection{University and Other Education Group}

The population engaged in the university and higher education group has the highest trip rate by public transport $(80 \%)$. No non-motorised trips are observed while $10 \%$ of walking trips are observed. These trips are owing to the presence of a university in the study area.

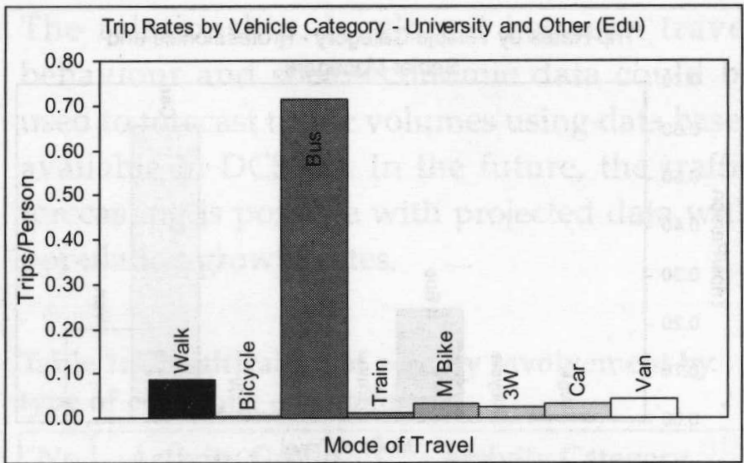

Figure 7: Trip Rate by University and Other Education Group

\subsection{Behaviour of Travel Pattern by Economically inactive Group}

This category of people is not involved directly with the economic activities in society. It is also the lowest trip making category in society. Less than $30 \%$ of such people make trips daily. This is very different from the other two categories. However between $35-40 \%$ of the total population in suburban areas belongs to this category and therefore has a significant effect on the number of trips in a zone.

\subsubsection{Housework Group}

Around $60 \%$ of the economically inactive population belongs to the household work category. Almost $100 \%$ of them are females. A major parts of these trips are, characteristically, market and shopping trips. They are rarely seen to use private motorised modes. Long distance trips are made by bus while short distance trips are made walking by this group of people, (Figure 8).

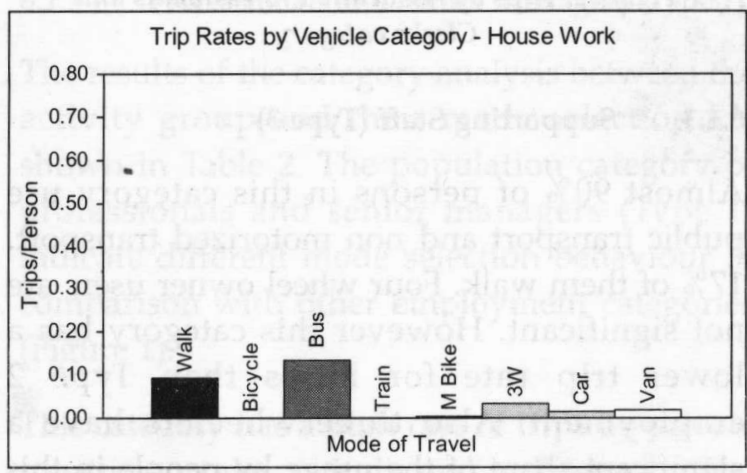

Figure 8: Trip Rate by Housework Group

\subsubsection{Retired Group}

Retired persons are those who make the highest trips among the economically inactive group. The major parts of these trips are observed to be 
social trips. They make good contributions to all types of modes. However, the public transport and walking modes have the major contribution to the share of the total trips.

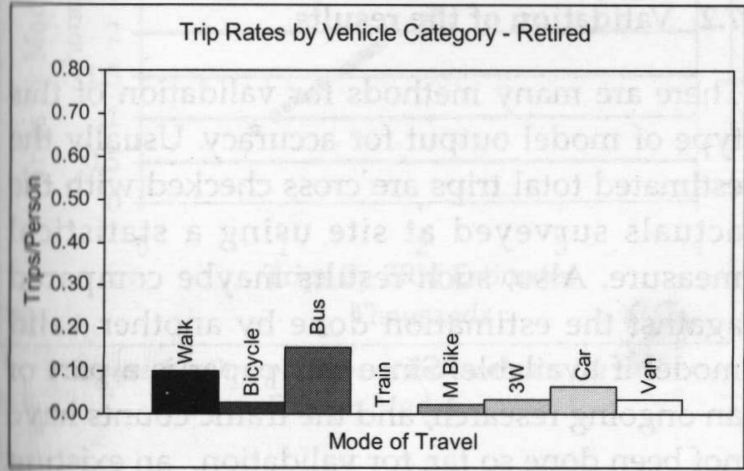

Figure 9: Trip Rate by Retired Group

\subsubsection{Unemployed Group}

The trip rate of unemployed persons is very similar to the housework group as can be seen when comparing Figures 8 and 10. They also basically depend on bus transport with a significant proportion seen to walk. This indicates their poor economic situation.

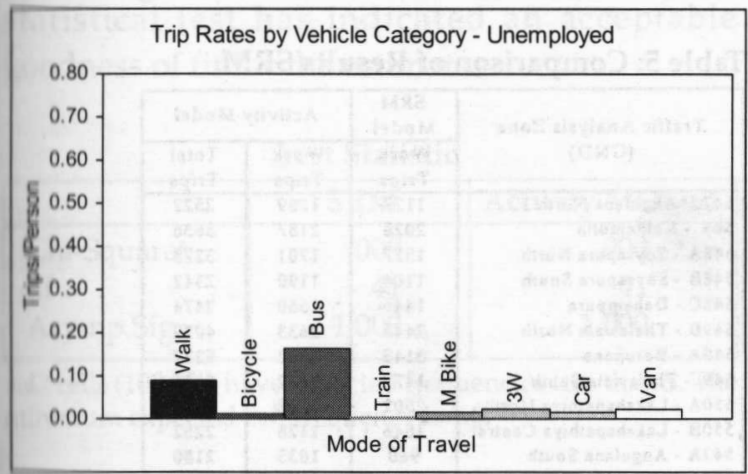

Figure 10: Trip Rate by Unemployed Group

\subsubsection{Non Active Group}

This is the lowest rate of trip makers found among all the different activity groups. They seem to rarely make trips and thus their trip rate is as low as $14 \%$. This means $86 \%$ of the population belonging to this category remains at home on a given day.

\subsection{Summary of the Characteristic Behaviour of Different activity groups}

The results of the above category analysis are given in Table 2. The trip rates of all categories discussed above is tabulated against the mode selection. These results can be used for

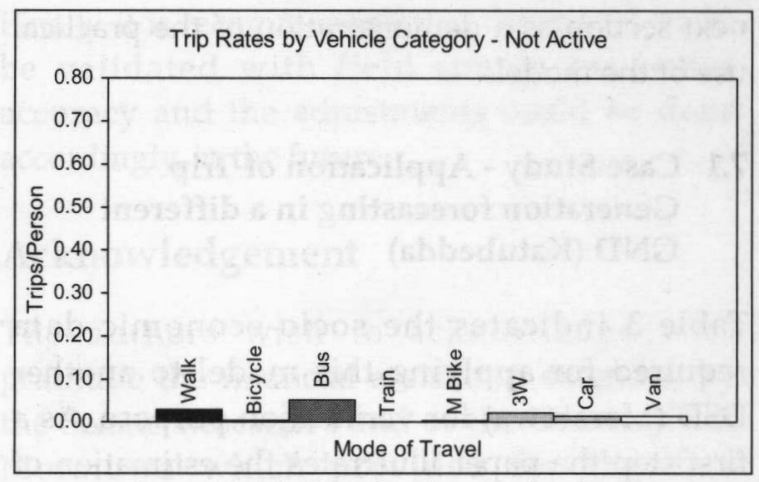

Figure 11: Trip Rate by Non Active Group

forecasting total trips by each mode based on the total population of each category given in DCS tables for suburban areas.

Table 2: Category Analysis of Trip Rates

\begin{tabular}{|c|c|c|c|c|c|c|c|c|c|c|c|}
\hline \multirow[b]{2}{*}{ Activity Type } & \multicolumn{8}{|c|}{ Total Trips By Mode } & \multirow{2}{*}{\multicolumn{2}{|c|}{ 苛 }} & \multirow[b]{2}{*}{$\%$} \\
\hline & 前 & 苋 & 苗 & 悬 & 曾 & 雍 & है & $\stackrel{5}{\longrightarrow}$ & & & \\
\hline Professionals and Senior & & & & & & & & & & & \\
\hline Managers & 6 & 0 & 115 & 10 & 8 & 10 & 303 & 95 & 548 & & \\
\hline $\begin{array}{l}\text { Associate Professionals } \\
\text { and Clerks }\end{array}$ & 53 & 10 & 537 & 36 & 107 & 31 & 82 & 79 & 936 & 4042 & 53 \\
\hline Supporting Staff & 425 & 100 & 1090 & 26 & 128 & 464 & 28 & 98 & 2358 & & \\
\hline Own Business & 27 & 6 & 66 & 1 & 29 & 20 & 22 & 30 & 199 & & \\
\hline Pre - School & 85 & 1 & 32 & 1 & 13 & 18 & 11 & 25 & 185 & & \\
\hline School & 348 & 11 & 655 & 13 & 31 & 111 & 49 & 381 & 1599 & 2751 & 36 \\
\hline University and Other & 87 & 5 & 730 & 10 & 34 & 24 & 34 & 44 & 967 & & \\
\hline Housework & 167 & 1 & 237 & 2 & 7 & 62 & 24 & 33 & 533 & & \\
\hline Retired & 27 & 7 & 42 & 0 & 6 & 9 & 17 & 9 & 117 & 827 & 11 \\
\hline Unemployed & 23 & 3 & 42 & 1 & 4 & 6 & 4 & 6 & 89 & & \\
\hline Non Active & 17 & 1 & 31 & 1 & 2 & 13 & 9 & 9 & 82 & & \\
\hline Total & 1264 & 145 & 3578 & 100 & 369 & 767 & 583 & 808 & 7613 & 7613 & 100 \\
\hline
\end{tabular}

\section{Results}

A trip generation by a given mode $m$ for a given traffic analysis zone $\mathrm{i}$ can be expressed as a linear function :

$$
\begin{aligned}
T_{i m}= & a_{m} E p 1_{i}+b_{m} E p 2_{i}+c_{m} E p 3_{i}+d_{m} B p_{i} \\
& +e_{m} P s p_{i}+f_{m} S p_{i}+g_{m} U p_{i}+h_{m} H w p_{i} \\
& +i_{m} R p_{i}+j_{m} U e p_{i}+k_{m} N p_{i}
\end{aligned}
$$

Where

$a_{m \prime} b_{m \prime} c_{m \prime} \ldots$ are the trip rates by a given mode, based on each category of activity group as given in Table 2 and where the other abbreviations used in the formula are defined in Table 3.

Hence the Total trips generated in a given zone can be expressed as

$T_{i}=\sum_{m=1}^{n} T_{i m}$

A work example and results for a different TAZ selected outside the base area is discussed in the 
next section as a demonstration of the practical use of the model.

\subsection{Case Study - Application of Trip Generation forecasting in a different GND (Katubedda)}

Table 3 indicates the socio-economic data required for applying this model to another DSD (Moratuwa) for verification purpose. As a first step the paper illustrates the estimation of trip generation for a TAZ which is a GND in Moratuwa DSD.

Table 3: Population by different activity engagement of a different suburban area (Katubedda GND)

\begin{tabular}{|l|c|c|}
\hline \multicolumn{1}{|c|}{ Activity Type } & Lable & Zonal Population \\
\hline Professionals and Senior & Ep1 & 495 \\
Managers & & \\
Associate Professionals & Ep2 & 902 \\
and Clerks & Ep3 & 2523 \\
Supporting Staff & Bp & 194 \\
Own Business & Psp & 199 \\
Pre - School & Sp & 1466 \\
School & Up & 1020 \\
University and Other & Hwp & 1780 \\
Housework & Rp & 268 \\
Retired & Uep & 261 \\
Unemployed & Np & 592 \\
Non Active & \\
\hline
\end{tabular}

The estimation of the total trip generation by different modes based on the model for the selected GND (Katubedda) are given in Table 4.

Table 4: Total Trip Generation by Mode in Selected TAZ' (Katubedda).

\begin{tabular}{|c|c|c|c|c|c|c|c|c|c|c|c|}
\hline \multirow[b]{2}{*}{ Activity Type } & \multicolumn{8}{|c|}{ Total Trips By Mode } & \multirow{2}{*}{\multicolumn{2}{|c|}{ 竎 }} & \multirow[b]{2}{*}{$\%$} \\
\hline & $\frac{\mu}{3}$ & 蜜 & 蛋 & 昱 & 涚 & 雍 & है & $\stackrel{5}{5}$ & & & \\
\hline $\begin{array}{l}\text { Professionals and Senior } \\
\text { Managers }\end{array}$ & 6 & 0 & 115 & 10 & 8 & 10 & 303 & 95 & $5 \div 3$ & & \\
\hline $\begin{array}{l}\text { Associate Professionals } \\
\text { and Clerks }\end{array}$ & 53 & 10 & 537 & 36 & 107 & 31 & 82 & 79 & 936 & 4042 & 53 \\
\hline Supporting Staff & 425 & 100 & 1090 & 26 & 128 & 464 & 28 & 98 & 2358 & & \\
\hline Own Business & 27 & 6 & 66 & 1 & 29 & 20 & 22 & 30 & 199 & & \\
\hline Pre-School & 85 & 1 & 32 & 1 & 13 & 18 & 11 & 25 & 185 & & \\
\hline School & 348 & 11 & 655 & 13 & 31 & 111 & 49 & 381 & 1599 & 2751 & 36 \\
\hline University and Other & 87 & 5 & 730 & 10 & 34 & 24 & 34 & 44 & 967 & & \\
\hline Housework & 167 & 1 & 237 & 2 & 7 & 62 & 24 & 33 & 533 & & \\
\hline Retired & 27 & 7 & 42 & 0 & 6 & 9 & 17 & 9 & 117 & & \\
\hline Unemployed & 23 & 3 & 42 & 1 & 4 & 6 & 4 & 6 & 89 & 821 & 11 \\
\hline Non Active & 17 & 1 & 31 & 1 & 2 & 13 & 9 & 9 & 82 & & \\
\hline Total & 1264 & 145 & 3578 & 100 & 369 & 767 & 583 & 808 & 7613 & 7613 & 100 \\
\hline
\end{tabular}

It can be seen that Katubedda GND which has a population of 9,700 has a daily estimated total trip generation of 7,613 trips. The employed categories make $53 \%$ of these trips while educational and inactive categories make $36 \%$ and $11 \%$ respectively. When this is estimated for other GNDs in the Moratuwa DSD area, it was observed that there was a significant variation of these estimated values for different GNDs.

\subsection{Validation of the results}

There are many methods for validation of this type of model output for accuracy. Usually the estimated total trips are cross checked with the actuals surveyed at site using a statistical measure. Also, such results maybe compared against the estimation done by another valid model if available. Since this paper is a part of an ongoing research, and the traffic counts have not been done so far, for validation, an existing trip generation model is used for comparison of results with this estimation model [6].

The estimated total trips by employees with the developed model and total work trip estimated using the Seoul Regression Model (SRM) [6] are tabulated in Table 5 . These estimates are very much close to the estimates from the model for the employed population. The comparison of work trip estimates of the model against those from the SRM estimates is shown in Figure 12.

Table 5: Comparison of Results SRM.

\begin{tabular}{|c|c|c|c|}
\hline \multirow{2}{*}{$\begin{array}{c}\text { Traffic Analysis Zone } \\
\text { (GND) }\end{array}$} & \multirow{2}{*}{$\begin{array}{c}\text { SRM } \\
\text { Model } \\
\text { Work } \\
\text { Trips }\end{array}$} & \multicolumn{2}{|c|}{ Activity Model } \\
\hline & & $\begin{array}{l}\text { Work } \\
\text { Trips }\end{array}$ & $\begin{array}{l}\text { Total } \\
\text { Trips }\end{array}$ \\
\hline 547 - Angulana North & 1177 & 1269 & 2522 \\
\hline $548 \cdot$ Kaldemulla & 2028 & 2187 & 3636 \\
\hline 548A - Soysapura North & 1577 & 1701 & 3278 \\
\hline 548B - Soysapura South & 1104 & 1190 & 2342 \\
\hline 548C - Dahampura & 1446 & 1560 & 2474 \\
\hline 549B - Thelawala North & 2442 & 2633 & 4079 \\
\hline 549A-Borupana & 3145 & 3392 & 5277 \\
\hline 549 - Thelawala South & 1477 & 1592 & 2681 \\
\hline SSOA - Lakshapathiya North & 2502 & 2698 & 4082 \\
\hline 550B - Lakshapathiya Central & 1046 & 1128 & 2252 \\
\hline $547 \mathrm{~A}-$ Angulana South & 960 & 1035 & 2180 \\
\hline $552 \mathrm{~A} \cdot$ Uyana South & 1623 & 1750 & 3139 \\
\hline 552B - Uyana North & 1148 & 1238 & 2557 \\
\hline 557B - Rawathawatta South & 812 & 876 & 1597 \\
\hline 557 - Rawathawatta East & 1666 & 1797 & 3276 \\
\hline 550 - Lakshapathiya Sourh & 2107 & 2272 & 4109 \\
\hline $551 \mathrm{~B} \cdot$ Kuduwamulla & 1069 & 1152 & 2238 \\
\hline $551-$ Katubedda & 3748 & 4042 & 7613 \\
\hline 551A $\cdot$ Molpe & 1718 & 1852 & 4160 \\
\hline $551 \mathrm{C} \cdot$ Moratumulla North & 1072 & 1156 & 2359 \\
\hline $558 \mathrm{~A} \cdot$ Kadalana & 1224 & 1320 & 2544 \\
\hline 557A-Rawathawatta West & 1482 & 1598 & 2823 \\
\hline 552 - Idama & 1311 & 1414 & 2411 \\
\hline 553C-Uswatta & 816 & 880 & 1777 \\
\hline 553 - Moratuwella South & 1420 & 1531 & 3137 \\
\hline 559 - Indibedda West & 1241 & 1339 & 2790 \\
\hline 558 - Moratumulla East & 1277 & 1377 & 2908 \\
\hline 558B - Moratumulla West & 1151 & 1241 & 2438 \\
\hline 560/6-Villorawatta East & 1186 & 1279 & 2525 \\
\hline 560/6-Villorawatta West & 1331 & 1436 & 2858 \\
\hline 559A - Indibedda East & 1052 & 1135 & 2383 \\
\hline 553 A - Moratuwella North & 1228 & 1325 & 2175 \\
\hline 553B - Moratuwella West & 727 & 784 & 1727 \\
\hline \$54 - Koralawella North & 1617 & 1744 & 3798 \\
\hline 554B - Koralawella East & 755 & 815 & 1546 \\
\hline $554 \mathrm{C}$ - Koralawella West & 1182 & 1275 & 2569 \\
\hline $554 \mathrm{~A}$-Koralawella South & 1220 & 1315 & 2757 \\
\hline 555 - Katukurunda North & 1155 & 1246 & 2669 \\
\hline 555A-Katukurunda South & 1485 & 1602 & 3287 \\
\hline 556 - Egoda Uyana North & 1523 & 1642 & 3424 \\
\hline $556 \mathrm{~A}$ - Egoda Uyana Central & 1066 & 1149 & 2323 \\
\hline 556B. Egoda Uyana South & 1596 & 1721 & 3982 \\
\hline
\end{tabular}




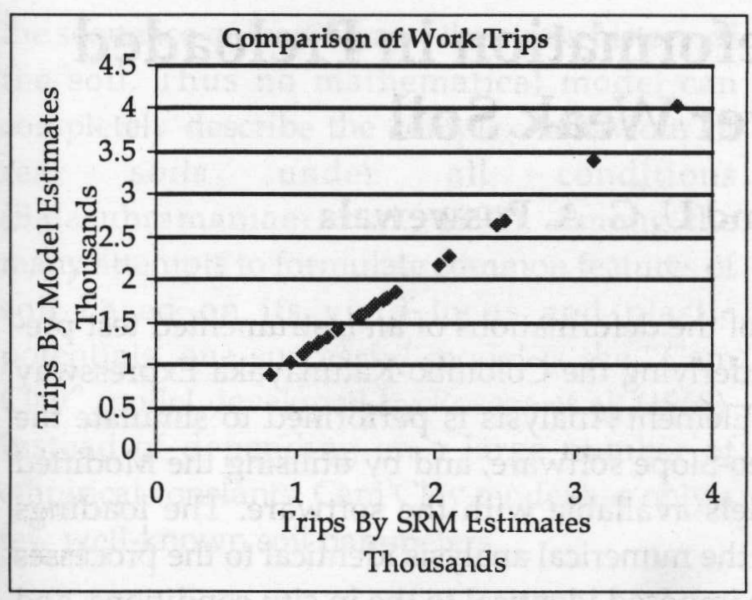

Figure 12: Comparison of Estimates with the Foreign Model.

The above comparison is statistically tested with Chi-square distribution using SPSS software. SRM model estimates are assumed as observed values for the statistical test.

Large values for Chi-Square of the test statistic indicate large discrepancies. The test statistics table has shown a very good fit between model and observed data. Relatively large significance values (>.10) indicate a reasonably good fit of the model to the observed data. Therefore the statistical test has indicated an acceptable goodness of fit for the estimates.

\begin{tabular}{|l|c|c|}
\multicolumn{3}{|c}{ Iest Statistic } \\
\hline & SRM & Activity MODEL \\
\hline Chi-Square & .000 & .000 \\
df & 41 & 41 \\
Asymp.Sig. & 1.000 & 1.000 \\
\hline
\end{tabular}

a. 42 cells $(100.0 \%)$ have expected frequencies less than 5 . The minimum expected cell frequency is 1.0.

\section{Conclusions}

The activity based trip generation analysis could be used for forecasting traffic in suburban areas, cost effectively, with DCS data bases which are released from time to time. The trip rates estimated for each mode of transport in this analysis is assumed not to vary with time in the short term, unless there is a major variation of transport supply in suburban areas. The trip rates should be revised accordingly in such situations.

Validation has been done, comparing the estimated figures, with results obtained by running an already existing model, where a very high degree of fit has been observed.
Finally it is recommended that the model could be validated with field counts for better accuracy and the adjustments could be done accordingly, in the future.

\section{Acknowledgement}

The authors wish to acknowledge with gratitude the financial assistance extended by the Senate Research Fund of the University of Moratuwa which provided for the data collection of the research.

\section{References}

1. Anderson M.D., "Travel Modelling for Smaller Urban Areas Using a Single Trip Purpose", University of Alabama in Huntsville, 2000

2. Census of Population and Housing 2001, Colombo District Final Results, A publication by Department of Census and Statistics of Sri Lanka, 2001.

3. Charles L. Purvis, "Incorporating Land Use and Accessibility variables in Travel Demand Models", Conference proceedings on Transportation, Land Use, and Air Quality, Portland, Oregon, 1998.

4. Goulias, Konstandinos G., and Ryuichi Kitamura, 'Travel Demand Forecasting with Dynamic Microsimulation', Transportation Research Record 1357, Transportation Research Board, pp $8-17,1992$

5. http://en.wikipedia.org/wiki/Urban_Planning, last visited 2nd March 2006.

6. Jongho RHEE, "Improvement of Trip Generation Forecast with Category Analysis in Seoul Metropolitan Area", Kyonggi University, South Korea, 2003.

7. Kanfani, A. K.., Transportation Demand Analysis, University of California, Berkley, 1983, pp.87-114.

8. Khisty, C.J and M.Y.Rahi. "Evaluation of three Inexpensive Travel Demand Models for Small Urban Areas" Transportation Research Record No. 1283. p.70- 78, 1987.

9. Liyanage and Kumarage, "Use of Electricity Consumption as an input for Cost Effective Traffic Forecasting" Annual sessions proceedings of Institute of Engineers Sri Lanka, 2006.

10. Muglar, Larry G., and Terence T. Quinn, Chapter 6: Regional Planning "Activity - Allocation Modelling", In Urban Planning and Development Applications of GIS, Edited by: S.Easa and Y Chan, ASCE, 1999.

11. Waddel et al, "Design of an Integrated Land Use and Activity-Based Travel Model System for the Puget Sound Region", University of Washington, USA, 2001. 